\title{
Impact of weather conditions on childhood admission for wheezy chest and bronchial asthma
}

\author{
Miami Kadhim Yousif*1, Abdul-Haleem Ali Al Muhyi² \\ Received: 10 Apr 2018 \\ Published: 28 Aug 2019
}

\section{Abstract}

Background: Climate change represents a possible threat to patients with bronchial asthma. The purpose of this study was to investigate any association between specific meteorological conditions and the rate of hospital admission for bronchial asthma and wheezy chest.

Methods: A retrospective study was conducted to observe the effects of changes in some meteorological variables on children aged 1-13 years with bronchial asthma and wheezy chest. Data were obtained from hospital registries for the study period involving all patients admitted with the diagnosis of wheezy chest and bronchial asthma. The meteorological data were obtained from the Iraqi World Meteorological Organization and Seismology and consisted of the mean monthly values of humidity, rain, temperature, dust, wind, and thunderstorms. The correlation between the mean monthly admission for bronchial asthma and changes in weather variables were investigated.

Results: There were 1043 admissions for asthma or wheezy chest (7.76\%). Out of all asthma cases, $75 \%(n=783)$ were $1-5$ years, while $25 \%(\mathrm{n}=260)$ were $6-13$ years. Male patients predominate $67.8 \%$, with a male to female ratio of $2: 1$. Hospital admissions for asthma and wheezy chest showed a seasonal variation especially for younger children. Higher monthly admission rates were associated with high relative humidity, rain, increase in wind speed, and lower temperature, whereas rising dust and thunderstorms did not show notable effects on children's admission for asthma.

Conclusion: The findings suggested that changes in weather conditions, especially high relative humidity and cold weather, may trigger asthma attacks especially in younger children, and thus protective measures are recommended for at risk children.

Keywords: Childhood asthma, Climate change, Wheezy chest

Conflicts of Interest: None declared

Funding: None

*This work has been published under CC BY-NC-SA 1.0 license.

Copyright $\odot$ Iran University of Medical Sciences

Cite this article as: Yousif MK, Al Muhyi AA. Impact of weather conditions on childhood admission for wheezy chest and bronchial asthma. Med J Islam Repub Iran. 2019 (28 Aug);33:89. https://doi.org/10.47176/mjiri.33.89

\section{Introduction}

Bronchial asthma is a disease syndrome with a global increase in prevalence (1), affecting an estimated $4 \%$ to $7 \%$ of the people worldwide. Childhood bronchial asthma varies widely from country to country. At the age of 6 to 7 years, the prevalence ranges from $4 \%$ to $32 \%(2,3)$.

Apart from being the leading cause of hospitalization for children, bronchial asthma is one of the most im-

Corresponding author: Dr Miami Kadhim Yousif, miamiyousif@yahoo.com

1. Department of Pediatrics, College of Medicine, University of Basrah, Iraq

2. Department of Marine Physics, Marine Science Center, University of Basrah, Iraq portant chronic conditions causing elementary school absenteeism $(2,4,5)$. Asthma is a chronic disorder of the bronchial tree, characterized by completely or partially reversible airway obstruction, which may improve spontaneously or may subside only after specific therapy $(6,7)$.

Bronchial obstruction is a result of bronchial muscle constriction, acting through the $\beta$-receptors, as well as

$\uparrow$ What is "already known" in this topic:

Climate change represents a possible threat to patients with bronchial asthma. Literature reports show the relationship between the development and exacerbation of asthma attacks and the meteorological observations. However, no previous study was done in Basra to show this relationship.

\section{$\rightarrow$ What this article adds:}

This study showed that changes in weather conditions, especially high relative humidity, rain, and cold weather, can trigger or worsen asthma attacks, especially in younger children. Thus, applying protective measures required. 
mucosal edema and increased airways secretions resulting from airways inflammation, all of which contribute to reducing airway flow. The obstruction to airway flow is reflected in reduced lung function and classical symptoms such as wheezing, dyspnea, and coughing (8). Asthma not only does harm to children's physical and mental health but also results in a heavy burden to patients' family and society $(9,10)$.

The risks of developing asthma depend on a complex interaction of hereditary and environmental factors. Risk factors are as follow: genetic predisposition (family history of atopy or asthma); perinatal factors (low birth weight, prematurity); exposure to allergens; infections (respiratory infections, especially those caused by respiratory syncytial virus); environmental air pollution; tobacco smoke; diet; and obesity $(11,12)$.

The association between asthma morbidity and meteorological conditions is well documented (13). There is clear evidence that the climate is changing at an increasing rate. Global average temperature has increased by more than 0.7 Co over the past 100 years. Extreme weather events, such as heat waves, heavy precipitation, and thunderstorms, are also predicted to increase over the next few decades (14).

Many literature reports show the relationship between the development and exacerbation of asthma attacks and the meteorological observation (14-16). However, it is not clear to what extent more specific meteorological variables are implicated in triggering asthma exacerbation (13).

There is evidence that changes in temperature, barometric pressure, rising dust, and relative humidity have some influence on the worsening of asthmatic symptoms (13), as triggers for deterioration and admission to hospital. Therefore, the objective of this study was to investigate any association between specific meteorological conditions and the rate of hospital admission for bronchial asthma and wheezy chest.

\section{Methods}

This retrospective study was conducted to observe the effects of changes in some meteorological variables on children with bronchial asthma and wheezy chest.
Patients: All children aged 1-13 years who were admitted to the pediatric ward of Almawani hospital in Basra who were diagnosed with asthma and had a history of recurrent attacks of breathlessness and wheezing, and young children with recurrent wheeze were selected during January 2014 to December 2016. The participants were classified into 2 groups according to their age: 1-5 and 6-13 years. Infants and patients with acute bronchiolitis were excluded from the study.

Data collection: Patients' data were obtained from hospital registries of Al Mawani hospital for the study period which included age, sex, date of admission, and diagnosis. The meteorological data were obtained from the records of the Iraqi World Meteorological Organization and Seismology and consisted of mean monthly values of meteorological variables, including mean temperature $(\mathrm{T})$, relative humidity (RH), rising dust, wind, rain, and thunderstorm.

\section{Results}

The total number of pediatric admissions during the study period was 13425 , out of them 1043 admissions were for asthma or wheezy chest (7.76\%). Also, 75\% $(n=783)$ of the participants were 1-5 years old, while $25 \%$ $(n=260)$ were $6-13$ years old. Of the patients, $67.8 \%$ $(n=708)$ were male, with male to female ratio of $2: 1$. Mean monthly values of childhood hospital admission for asthma and wheezy chest and mean monthly values of the meteorological variables for each year of the study period were studied. Admissions varied. The variation of the mean monthly hospital admission rates for the 3 age groups is shown in Figure 1.

Variations of monthly hospital admission rates for the 3 age groups and the association with the variation in the mean relative humidity mean temperature, rain, and wind speed are shown in Figures 2, 3, 4, and 5.

A descriptive summary of the mean monthly values of admission and meteorological variables is presented in Table 1. The results of Pearson's correlation between the mean monthly admission for asthma or wheezy chest for each age group and the meteorological variables are demonstrated in Table 2.

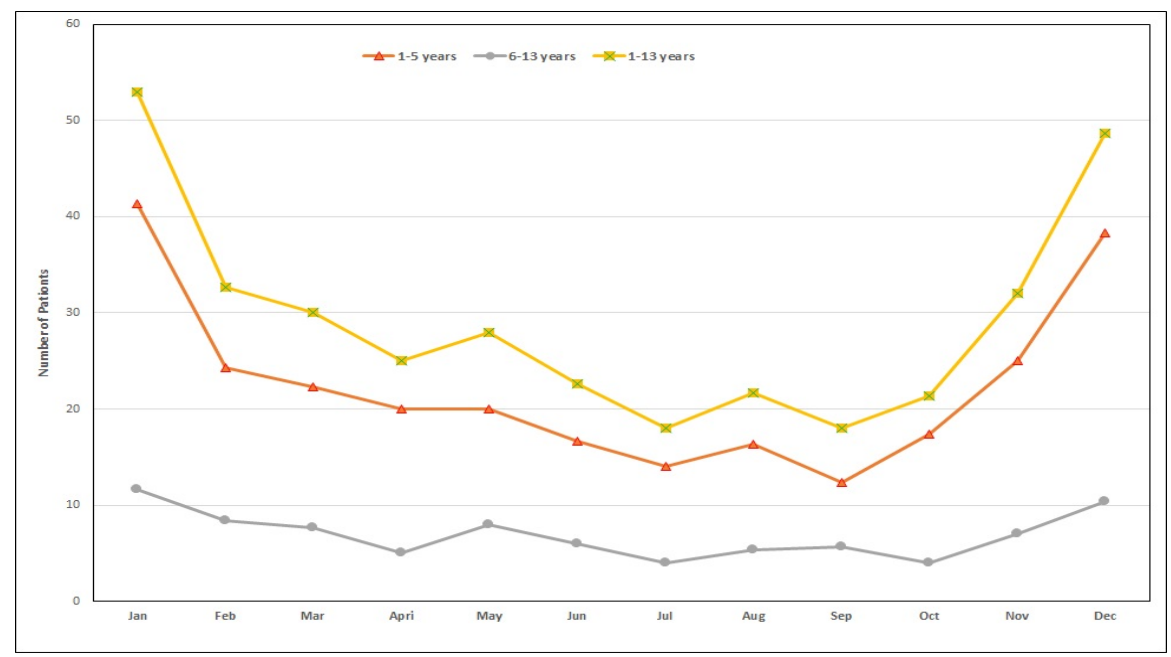

Fig. 1. Seasonal variation of mean monthly values of hospital admission for asthma of the 3 age groups 


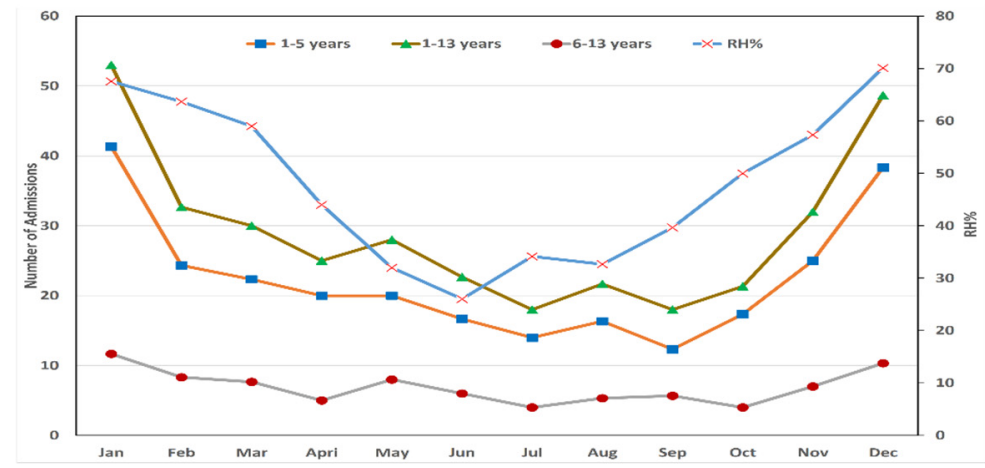

Fig. 2. Mean monthly admission rates of the 3 age groups and mean monthly relative humidity

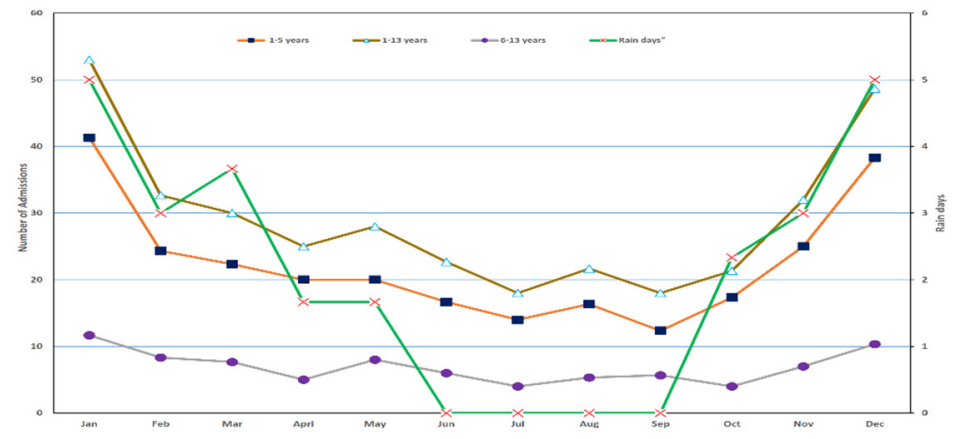

Fig. 3. Mean monthly admission rates of the 3 age groups and mean monthly rainy days

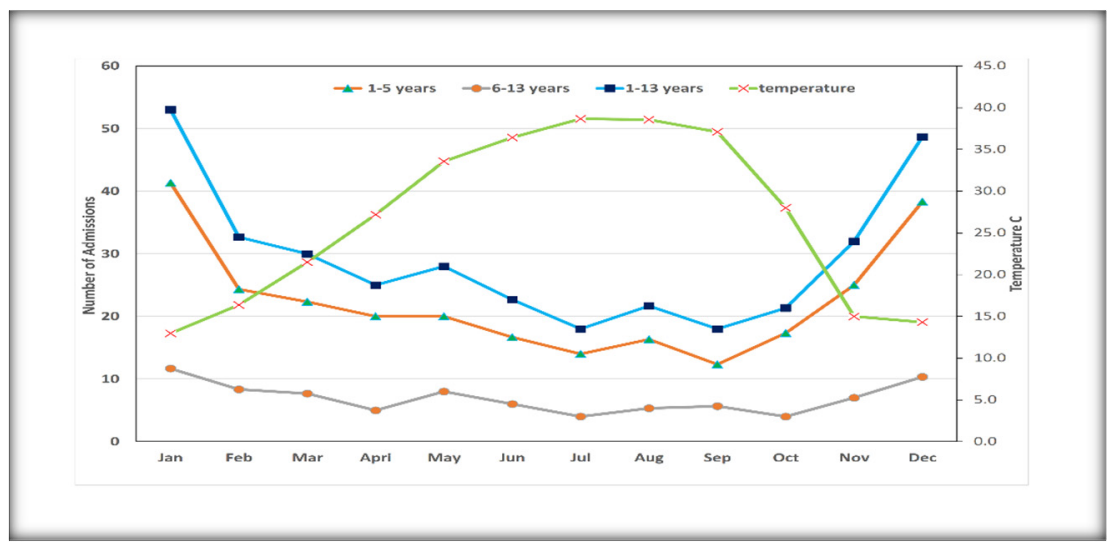

Fig. 4. Mean monthly admission rates of the 3 age groups and mean monthly temperature

\section{Discussion}

Based on the results of this study, hospital admissions for childhood asthma and wheezy chest showed a seasonal variation, with late autumn and early winter peak. This variation was more evident in children aged 1-5 years than older children (Fig. 1). Literature reviews have shown that seasonal variation has not been reported previously in childhood admission for asthma in Basra. In a study done in Athens, Greece, a notable pattern of seasonal variation of asthma admission, which was associated with weather conditions, was shown (13).
In the present study, the mean monthly rates of childhood admissions for bronchial asthma and wheezy chest was found to be associated with changes in certain weather variables.

The role of weather (pressure, temperature, and humidity) on the initiation and/or exacerbation of respiratory allergic symptoms in predisposed individuals is still poorly understood. Weather affects asthma directly by acting on the airways, or indirectly, by airborne allergens and pollutant levels (14).

In the present study, variation in the mean monthly ad- 


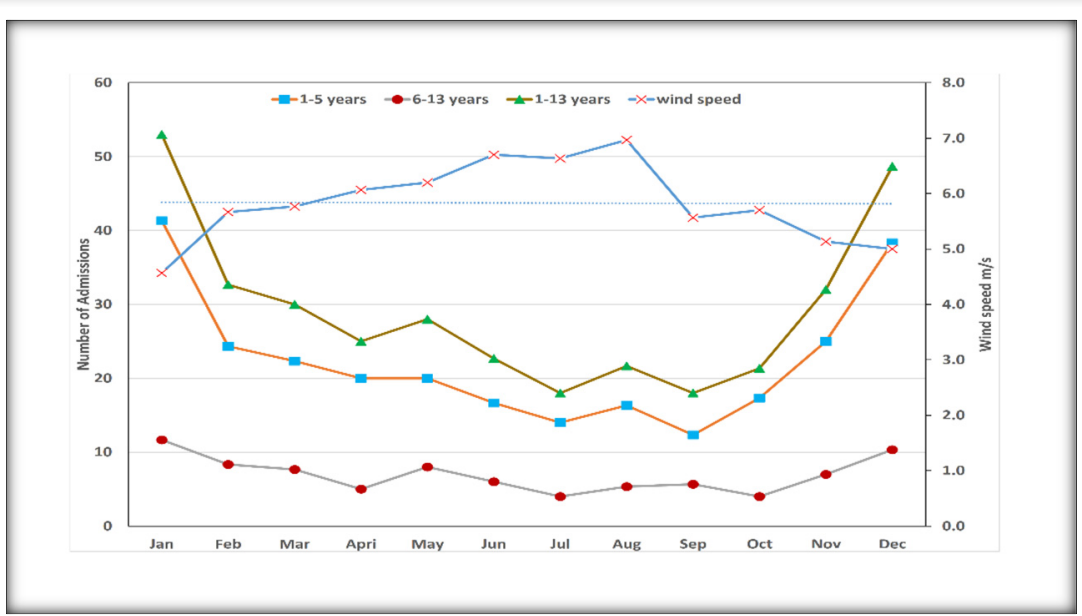

Fig. 5. Mean monthly admission rates of the 3 age groups and mean monthly wind speed

Table 1. Descriptive statistics

\begin{tabular}{lccc}
\hline & Mean & Std. Deviation & $\mathrm{N}$ \\
\hline Total Admission & 29.33 & 11.316 & 12 \\
Temperature & 26.650 & 10.2196 & 12 \\
Number of Rain Days & 2.17 & 1.899 & 12 \\
Wind Speed & 5.842 & 0.7229 & 12 \\
Relative Humidity & 48.08 & 15.335 & 12 \\
\hline
\end{tabular}

Table 2. Pearson's correlation coefficients between the mean monthly hospital admission rates for asthma and the meteorological variables by age group

\begin{tabular}{lccccc}
\hline Age & & Temperature & RH & $\begin{array}{c}\text { Rainy } \\
\text { days }\end{array}$ & Wind Speed \\
\hline 1-13 years & Pearson Correlation & $-0.837^{* *}$ & $0.795^{* *}$ & $0.890^{* *}$ & $-0.763^{* *}$ \\
& Sig. (2-tailed) & 0.001 & 0.002 & 0.000 & 0.004 \\
1-5 years & Pearson Correlation & $-0.847^{* *}$ & $0.800^{* *}$ & $0.894^{* *}$ & $-0.770^{* *}$ \\
& Sig. (2-tailed) & 0.001 & 0.002 & 0.000 & 0.003 \\
6-13 years & Pearson Correlation & $-0.729^{* *}$ & $0.686^{*}$ & $0.811^{* *}$ & $-0.717^{* *}$ \\
& Sig. (2-tailed) & 0.007 & 0.014 & 0.001 & 0.009 \\
\hline
\end{tabular}

**. Correlation is significant at the 0.01 level (2-tailed).

*. Correlation is significant at the 0.05 level (2-tailed).

mission rates for asthma and wheezy chest was found to be associated with the seasonal variation in relative humidity and rain, and more admissions were associated with high humidity and rainy days (Figs. 2 and 3).

Pearson's correlation between the mean monthly hospital admission rates for asthma and the meteorological variables showed that the mean monthly admission rates have a positive association with high humidity and more rainy days and were more significant in young age group (Table 2). In Greece, the results of a study showed that relative humidity was an implicated meteorological variable for younger asthmatic children (13). Also, a study in Turkey found that asthma, wheezing, and allergic rhinitis was associated with higher mean yearly outdoor humidity among school children (17).

Rain or humidity may induce hydration and fragmentation of pollen grains, which releases allergenic biological aerosols into the atmosphere (14). Fungal spore counts of Cladosporium in the atmosphere are correlated with relative humidity, and their concentration has been reported to account for a significant proportion of the asthma exacerbation in children $(13,18,19)$.

The growth of house dust mites is strongly associated with relative humidity as mites thrive in humid environments (20).

In this study, it was also observed that low temperatures had effects on hospital admission for asthma. When the mean temperature was relatively low, the number of asthma hospital admissions was higher and had a peak in the cold months of the year (November, December, and January) (Fig. 4). The mean monthly admission rate for asthma was inversely correlated with the mean temperature, which is consistent with the finding of a study by $\mathrm{D}$, Hervása et al. They observed that the mean temperature was inversely correlated with emergency department visits for asthma (21), and this was more noticeable in children younger than 5 years (Table 2) and contradictory to what was reported by Mohr et al. (22), who observed a positive association in summer and a negative association during winter time.

Several studies have emphasized the relationship between low temperatures or cooling and asthmatic attacks. Cold temperature is a major environmental factor that exacerbates chronic inflammatory airway diseases (eg, chronic obstructive pulmonary and asthma) $(23,24)$.

Cold temperature has often been followed by an increase in bacterial and viral infections of the airways, infiltration of inflammatory factors, and mucus secretion $(23,25,26)$. Reduced temperatures often precedes the onset of infections (26), a finding that may explain, at least in part, the effects of the mean temperature on asthma (23). 
Other weather variables, including rising dust and thunderstorm, did not show notable effects on childhood admissions for asthma, possibly because data was on monthly basis; and thus, the short effect of some weather variables might have been lost. Therefore, conducting further studies to support the findings of this study is highly recommended.

\section{Conclusion}

The findings of this study suggest that high humidity, rain, wind, and cold temperature may trigger asthma attacks and that effective strategies are needed to protect at risk children.

\section{Conflict of Interests}

The authors declare that they have no competing interests.

\section{References}

1. Sumair A, Noor UI-Ain, Munir AS, Jammal AN, Tehseen K. Seasonal Changes and Children with Bronchial Asthma (2-15 Years Age) Reporting at Asthma Clinics of Mayo Hospital and Children Hospital, Lahore. J Fatima Jinnah Med Uni. 2012;6(3).

2. Ranabir P, Sanjay D, Shrayan P. Prevalence of Bronchial Asthma in Indian Children. Indian J Commun Med. 2009 Oct; 34(4):310-316.

3. International study of Bronchial Asthma and allergies in childhood (ISAAC) Worldwide variations in the prevalence of Bronchial Asthma symptoms. Euro Respir J. 1998;12:315-35.

4. Reid J, Marciniuk DD, Cockcroft DW. Bronchial Asthma management in the emergency department. Can Respir J. 2000;7:255-60.

5. Gürkan F, Ece A, Haspolat K, Derman O, Bosnak M. Predictors for multiple hospital admissions in children with Bronchial Asthma. Can Respir J. 2000;7:163-6.

6. van Aaderen WM. Childhood Asthma: Diagnosis and Treatment. Scientifica. $2012 ; 2012$.

7. "GINA report," Global Strategy for Asthma Management and Prevention, 2011, http://www.ginasthma.org/

8. Lødrup Carlsen KC, Pijnenburg MW. Monitoring asthma in childhood. Eur Respir Rev. 2015; 24:178-186.

9. Ya-Feng R, Hong Li, Xiao-Hong X, Hai-Shan G, Bo-Ai Z, ChuanLiang $\mathrm{C}$, et al. Preliminary study on pathogenesis of bronchial asthma in children. Pediatr Res. 2015;77(4):506-510.

10. Ji M, Cai S. Nursing of bronchial asthma in children. J Nur Sci. 2005;20:68-70.

11. Anuradha A, Lakshmi Kalpana V, Narsingarao S. Epidemiological Study on Bronchial Asthma Indian $\mathrm{J}$ Allergy Asthma Immunol. 2011;25(2):85-89.

12. Bracken MB, Belanger K, Cookson WO, Triche E, Christiani DC, Leaderer BP. Genetic and perinatal risk factors for asthma onset and severity: a re-view and theoretical analysis. Epidemiol Rev. 2002;24:176-189.

13. Priftis KN, Paliatsos AG, Panagiotopoulou-Gartagani P, TapratziPotamianou P, Zachariadi-Xypolita A, Nicolaidou P, et al. Association of Weather Conditions with Childhood Admissions for Wheezy Bronchitis or Asthma in Athens. Respiration. 2006;73:783-790.

14. Amato GD, Cecchi L, Amato MD, Licardi G. Urban Air Pollution and Climate Change as Environmental Risk Factor of Respiratory Allergy. J Investig Clin Immunol. 2010;20(2):95-102.

15. Weiland SK, Hüsing A, Strachan DP, Rzehak P, Pearce N, and the ISAAC Phase One Study Group. Climate and the prevalence of symptoms of asthma, allergic rhinitis, and atopic eczema in children Occup Environ Med. 2004;61(7):609-15.

16. Hashimoto M, Fukuda T, Shimizu T, Watanabe S, Watanuki S, Eto $\mathrm{Y}$, et al. Influence of climate factors on emergency visits for childhood asthma attack. Pediatr Int. 2004;46(1):48-52.

17. Kurt E, Metintas S, Basyigit I, Bulut I, Coskun E, Sennur D, et al. Prevalence and risk factors of allergies in Turkey: Results of an multicentric cross- sectional study in children. Pediatr Allergy Immunol. 2007; 18:566-574.
18. Katial RK, Zhang Y, Jones RH, Dyer PD. Atmospheric mold spore counts in relation to meteorological parameters. Int $\mathrm{J}$ Biometeorol. 1997 Jul;41(1):17-22.

19. Lewis SA, Corden JM, Forster GE, Newlands M. Combined effects of aerobiological pollutants, chemical pollutants and meteorological conditions on asthma admissions and A \& E attendances in Derbyshire UK, 1993-96. Clin Exp Allergy. 2000 Dec;30(12):1724-32.

20. Arlian LG. Water balance and humidity requirements of house dust mites. Exp Appl Akarol. 1992; 16:15-35.

21. Hervása D, Utrera JF, Hervás-Masip J, Hervás JA, García-Marcos L. Can meteorological factors forecast asthma exacerbation in a paediatric population? Allergol Immunopathol (Madr). 2013.

22. Mohr LB, Luo S, Mathias E, Tobing R, Homan S, Sterling D. Influence of season and temperature on the relationship of elemental carbon air pollution to pediatric asthma emergency room visits. J Asthma. 2008;45:936-43.

23. Li M, Li Q, Yang G, Kolosov VP, Perelman JM, Zhou XD. Cold temperature induces mucin hypersecretion from normal human bronchial epithelial cells in vitro through a transient receptor potential melastatin 8 (TRPM8)-mediated mechanism. J Allergy Clin Immunol. 2011;128:626-634: e625.

24. Zhang Y, Peng L, Kan H, Xu J, Chen R, Liu Y, et al. Effects of Meteorological Factors on Daily Hospital Admissions for Asthma in Adults: A Time-Series Analysis. PLoS One. 2014;9 (7),e102475

25. Donal dson G, Seemungal T, Jeffries D, Wedzicha J. Effect of temperature on lung function and symptoms in chronic obstructive pulmonary disease. Eur Respir J. 1999;13:844-849.

26. Larsson K, Tornling G, Gavhed D, Muller-Suur C, Palmberg L. Inhalation of cold air increases the number of inflammatory cells in the lungs in healthy subjects. Eur Respir J. 1998;12:825-830. 